\title{
Isomorphic response in a case of quinolone-induced acute generalized exanthematous pustulosis
}

\section{Reakcja izomorficzna u pacjenta z ostrą uogólnioną osutką krostkową wywołaną przez chinolon}

Konchok Dorjay, Soumya Sachdeva, Surabhi Sinha

Dr. Ram Manohar Lohia Hospital and Post Graduate Institute of Medical Education and Research, New Delhi, India

Dermatol Rev/Przegl Dermatol 2020, 107, 454-458

DOI: https://doi.org//0.5/14/dr.2020.101673

\author{
CORRESPONDING AUTHOR/ \\ ADRES DO KORESPONDENCJI: \\ Konchok Dorjay MBBS, DVD, \\ DNB \\ Dr. Ram Manohar Lohia Hospital \\ and Post Graduate Institute \\ of Medical Education \\ and Research \\ New Delhi, India \\ phone: 8800946147 \\ e-mail: konchokyokhang@gmail. \\ com
}

\begin{abstract}
Acute generalized exanthematous pustulosis is a severe, life-threatening, drug-induced cutaneous eruption that is associated with appearance of non-follicular sterile pustules on an erythematous base usually with oedema. We report a case of acute generalized exanthematous pustulosis induced by ofloxacin given for acute diarrhea. The patient was then treated successfully with oral glucocorticosteroids. However, what was notable was that he developed linear non-follicular pustules on the back indicating an isomorphic response (Koebner phenomenon) in acute generalized exanthematous pustulosis, which has not been reported before in the published English literature.
\end{abstract}

\section{STRESZCZENIE}

Ostra uogólniona osutka krostkowa jest ciężką, zagrażającą życiu dermatozą, w której dochodzi do wysiewu zmian skórnych w reakcji na leki. Zmiany mają postać jałowych krostek na podłożu rumieniowym i zwykle towarzyszy im obrzęk. Przedstawiamy przypadek ostrej uogólnionej osutki krostkowej wywołanej przez ofloksacynę podawaną pacjentowi z powodu ostrej biegunki. U chorego zastosowano doustne glikokortykosteroidy i uzyskano dobry efekt terapeutyczny. Prezentowany przypadek jest ciekawy ze względu na obecność linijnie ułożonych zmian krostkowych umiejscowionych na plecach, wskazujących na reakcję izomorficzną (objaw Koebnera) w przebiegu ostrej uogólnionej osutki krostkowej. Według naszej najlepszej wiedzy taki przypadek nie był dotychczas opisywany w anglojęzycznej literaturze medycznej.

Key words: acute generalized exanthematous pustulosis, quinolone, isomorphic response, Koebner phenomenon.

Słowa kluczowe: ostra uogólniona osutka krostkowa, chinolon, reakcja izomorficzna, objaw Koebnera. 
Acute generalized exanthematous pustulosis (AGEP) is a severe cutaneous adverse reaction, and multiple drugs, such as antibiotics, anticonvulsants, antimalarials, antifungals, and antihypertensives have been reported to cause the disease. Antibiotics of the penicillin group, macrolides and quinolones are most commonly implicated in causing this eruption.

\section{OBJECTIVE}

Here we report a 9-year-old child treated with ofloxacin for infective diarrhoea who developed AGEP and demonstrated the isomorphic response in it.

\section{CASE REPORT}

A 9-year-old child presented with a red, itchy rash that started on the chest followed by the abdomen and back and gradually involved the arms, thighs, legs and face, which progressed in that order in 3 days. The child had a history of trauma to the back and developed multiple clustered pustular lesions in a linear distribution over the site of injury around 2 days previously. He had a history of diarrhoea treated by ofloxacin. His past medical history was insignificant. Family history of dermatological disorders including psoriasis was negative.

On clinical examination, the child was febrile with PR 120/minute respiratory rate $24 / \mathrm{min}$ and blood pressure $100 / 60$ and had oxygen saturation $100 \%$ on room air. Dermatological examination revealed nonfollicular pustular eruptions on an erythematous background, most pronounced over the chest, nape of the neck and back (fig. 1). Erythema was most pro-
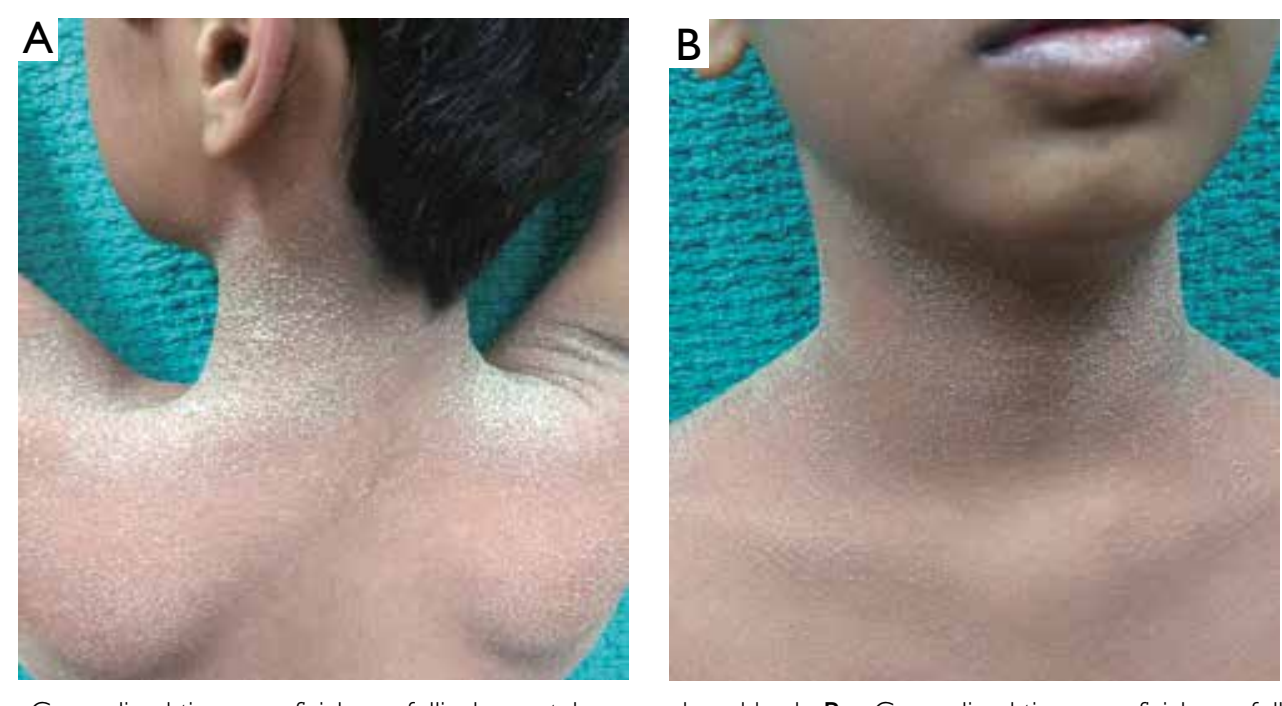

Figure I. A - Generalized tiny superficial non-follicular pustule on neck and back. B - Generalized tiny superficial non-follicular pustule on neck and chest

Rycina I. A - Uogólnione, drobne, powierzchowne krostki na szyi i plecach. B - Uogólnione, drobne, powierzchowne krostki na szyi i klatce piersiowej

\section{WPROWADZENIE}

Ostra uogólniona osutka krostkowa (acute generalized exanthematous pustulosis - AGEP) jest ciężką niepożądaną reakcją skórną, która może wystąpić w wyniku stosowania różnych leków, takich jak antybiotyki, leki przeciwdrgawkowe, przeciwmalaryczne, przeciwgrzybicze i przeciwnadciśnieniowe. Antybiotyki z grupy penicylin, makrolidy i chinolony są najczęstszymi czynnikami wywołującymi.

\section{CEL PRACY}

Przedstawiamy przypadek 9-letniego chłopca leczonego ofloksacyną z powodu biegunki zakaźnej, u którego rozwinęła się ostra uogólniona osutka krostkowa z reakcją izomorficzną.

\section{OPIS PRZYPADKU}

U 9-letniego chłopca wystąpiła czerwona, swędząca wysypka umiejscowiona początkowo na skórze klatki piersiowej. W czasie kolejnych 3 dni zajęta została również skóra brzucha i pleców, a następnie ramion, ud, podudzi i twarzy. Ustalono, że chłopiec doznał urazu pleców, a ok. 2 dni później w miejscu urazu rozwinęły się liczne skupiska zmian krostkowych o linijnym układzie.W wywiadzie u pacjenta występowała biegunka, którą leczono ofloksacyną. Poza tym nie stwierdzono istotnych obciążeń. Wywiad rodzinny w kierunku schorzeń dermatologicznych był ujemny.

W badaniu klinicznym stwierdzono gorączkę, tachykardię 120/min, częstość oddechów 24/min, ciśnienie tętnicze 100/60 mm Hg oraz saturacja $100 \%$. $\mathrm{W}$ badaniu dermatologicznym stwierdzono krost- 
nounced over the face and the extremities, wherein the pustules were less clustered. Linear clustered pustules over the back at the site of trauma were evident, indicating an isomorphic response (koebnerization) (fig. 2). The mucosae were not involved. Haematology revealed leucocytosis $(13,400)$, predominantly neutrophilic $(84 \%)$. The erythrocyte sedimentation rate (ESR) and C-reactive protein (CRP) were raised. The rest of the investigations were unremarkable. Histopathology of the lesions showed subcorneal pustules, oedema of the papillary dermis and perivascular infiltrates containing neutrophils and epidermal spongiosis (fig. 3). Thus, on the basis of the above findings, the diagnosis of AGEP was made. A short course of oral glucocorticosteroids was given. Emollients and antihistamines were used for itching and xerosis. The erythema improved within 5 days and no new fresh crop of pustular lesions appeared thereafter; hence the glucocorticosteroids were stopped after 1 week.

\section{DISCUSSION}

Acute generalised exanthematous pustulosis is a cutaneous reaction that is associated with drugs in the majority of cases and is usually severe. This can be associated with acute viral infections as well as mercury [1]. The condition usually rapidly develops within 48 hours of ingesting the offending medication and presents as sterile non-follicular pustular lesions on an erythematous background and oedema may

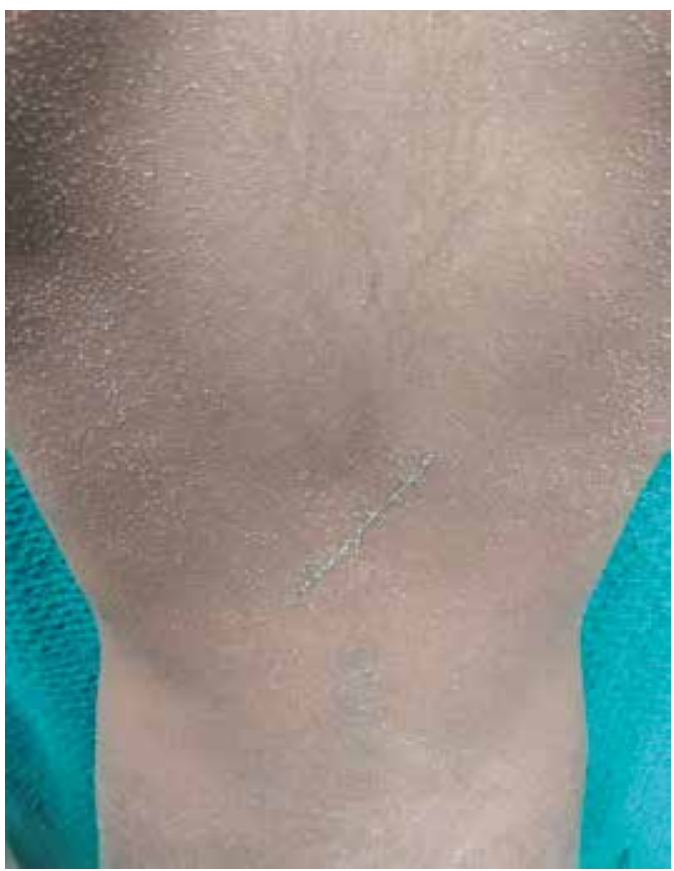

Figure 2. Linear pustules on the back (Koebner phenomenon)

Rycina 2. Linijnie ułożone skupiska krostek na plecach (objaw Koebnera) ki na podłożu rumieniowym, najbardziej nasilone na skórze klatki piersiowej, karku i pleców (ryc. 1). Rumień był najbardziej widoczny na twarzy i kończynach, a w tych lokalizacjach krostki były bardziej rozsiane. Na plecach, w miejscu urazu, widoczne były natomiast ułożone linijnie skupiska wskazujące na reakcję izomorficzną - objaw Koebnera (ryc. 2). Nie stwierdzono zajęcia błon śluzowych. W badaniach hematologicznych wykazano leukocytozę (13 400) z przewagą neutrofilów (84\%). Stwierdzono również podwyższone OB i CRP. W wynikach pozostałych badań nie odnotowano odchyleń od normy. W badaniu histologicznym stwierdzono występowanie krostek pod warstwą rogową, obrzęk warstwy brodawkowatej skóry właściwej oraz nacieki okołonaczyniowe zawierające neutrofile oraz spongioze (ryc. 3). Na podstawie tego obrazu ustalono rozpoznanie AGEP. W leczeniu wdrożono krótki cykl doustnie podawanych glikokortykosteroidów. Aby złagodzić świąd i suchość skóry, stosowano emolienty i leki przeciwhistaminowe. Ze względu na zmniejszenie nasilenia rumienia w czasie 5 dni oraz brak nowego wysiewu zmian krostkowych po upływie tygodnia odstawiono leczenie glikokortykosteroidami.

\section{DYSKUSJA}

Ostra uogólniona osutka krostkowa jest reakcją skórną, która w większości przypadków pojawia się w następstwie przyjmowania leków i ma zwykle ciężki przebieg. Może mieć związek z ostrymi zakażeniami wirusowymi, a także z kontaktem z rtęcią [1]. Zwykle rozwija się szybko - w czasie 48 godzin od przyjęcia leku indukującego zaburzenie. AGEP charakteryzuje się obecnością jałowych zmian krostkowych na podłożu rumieniowym, którym może towarzyszyć obrzęk [1]. Niekiedy u chorych stwierdza się leukocytozę z neutro-

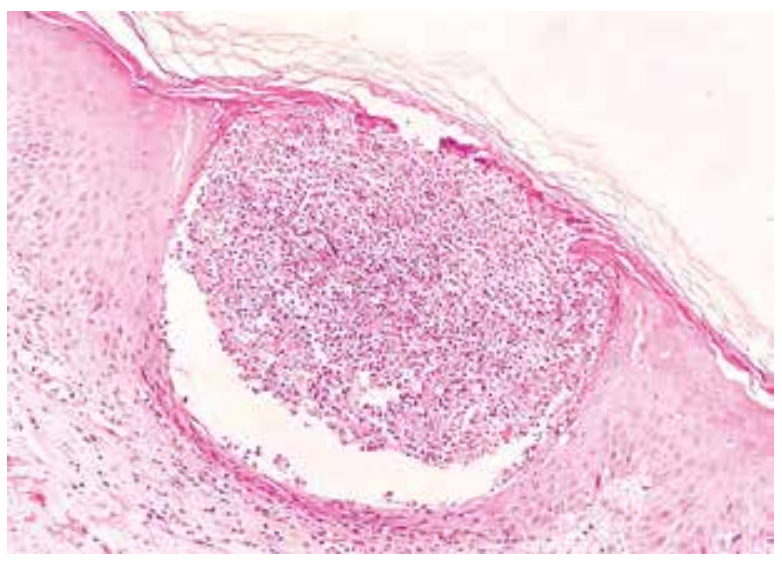

Figure 3. Spongiform subcorneal pustule with mixed neutrophils and eosinophils (haematoxylin-eosin, 100X)

Rycina 3. Gąbczasta krostka umiejscowiona pod warstwą rogową, zawierająca neutrofile i eozynofile (barwienie hematoksyliną i eozyną, powiększenie $100 \times$ ) 
be present [1]. There may be associated neutrophilic leucocytosis and fever; that was evident in our case as well [1]. There can also be a severe presentation that is associated with multisystemic involvement and associated mucous membrane involvement, which was however absent in our case [2]. The histopathologic examination is suggestive of spongiform subcorneal and/or intraepidermal pustules, marked papillary oedema, and polymorphous perivascular infiltrate with neutrophils and exocytosis of some eosinophils $[2,3]$. The lesions usually spontaneously resolve within 15 days [4].

AGEP developing after drug intake has been found to be associated with mutations in the interleukin-36RN (IL-36RN) gene, encoding the IL-36 receptor antagonist (IL-36Ra) [5]. However, studies are still ongoing to confirm whether IL-36RN leads to AGEP or drug-induced generalized pustular psoriasis [6]. Thus increasing IL-36 signalling predisposes to production of increased amounts of IL-6, IL-8, 1L-1a, IL-1b, leading to development of pustular crops [7]. Based on patch tests and some in-vitro tests, it is also hypothesised that AGEP is a type IV hypersensitivity reaction, leading to formation of drug-specific CD4 and CD8 cells [8].

The disorders associated with true koebnerization are psoriasis, vitiligo and lichen planus [9]. Behçet disease, Darier disease, erythema multiforme, granuloma annulare and Hailey-Hailey disease are often associated with Koebner's phenomenon. Koebnerization has been occasionally reported in Kaposi sarcoma, Kyrle's disease, lichen sclerosus et atrophicus, morphea, necrobiosis lipoidica, pellagra, perforating folliculitis and reactive perforating collagenosis as well [9].

An isomorphic response (Koebner phenomenon) has not been reported in the literature in association with AGEP. In the case of non-resolution of fever or high grade fever and longer periods of rash or its recurrence, one should consider generalized pustular psoriasis $[10,11]$. We present this case to add to the list of conditions known to demonstrate koebnerization and so that clinicians may be aware of this presentation.

\section{CONFLICT OF INTEREST}

The authors declare no conflict of interest. filią i gorączkę, które wystąpiły także w opisywanym przypadku [1]. Możliwa jest również ciężka postać choroby, przebiegająca z zajęciem wielu układów, a także błon śluzowych, czego jednak nie obserwowano u opisanego chłopca [2]. Badanie histopatologiczne wskazuje na obecność gąbczastych krostek pod warstwą rogową i/lub śródnaskórkowo, nasilony obrzęk warstwy brodawkowatej, okołonaczyniowy naciek z neutrofilów oraz egzocytozę eozynofilów [2, 3]. Zmiany te zwykle ustępują samoistnie w czasie 15 dni [4].

Wykazano, że AGEP wywoływana przez leki ma związek z obecnością mutacji w genie interleukiny 36RN (IL-36RN), kodującym antagonistę receptora IL-36 (IL-36Ra) [5]. Toczą się jednak badania, których celem jest ustalenie, czy IL-36RN prowadzi do AGEP czy wywołanej lekami uogólnionej łuszczycy krostkowej [6]. W tym mechanizmie wzrost IL-36 predysponuje do wytwarzania zwiększonych ilości IL-6, IL-8, IL-1a, IL-1b, wywołując wysiew skórnych zmian krostkowych [7]. Na podstawie testów płatkowych i niektórych testów in vitro wysunięto hipotezę, że AGEP jest reakcją nadwrażliwości typu IV, która prowadzi do powstawania swoistych dla leku limfocytów CD4 i CD8 [8].

Do schorzeń związanych z występowaniem zjawiska prawdziwej koebneryzacji zalicza się łuszczycę, bielactwo nabyte i liszaj płaski [9]. Objaw Koebnera może występować w chorobie Behçeta, chorobie Dariera, rumieniu wielopostaciowym, ziarniniaku obrączkowym oraz chorobie Haileya-Haileya. Istnieją doniesienia o sporadycznym występowaniu koebneryzacji u pacjentów z mięsakiem Kaposiego, chorobą Kyrlego, liszajem twardzinowym i twardziną ograniczoną, tłuszczowym obumieraniem skóry, pelagrą, perforującym zapaleniem mieszków włosowych i nabytą perforującą dermatozą (reaktywną perforującą kolagenozą) [9].

W piśmiennictwie nie ma doniesień o reakcji izomorficznej (objawie Koebnera) towarzyszącej AGEP. W przypadku wysokiej, nieustępującej gorączki, utrzymywania się zmian skórnych lub ich nawrotów należy rozważyć rozpoznanie uogólnionej łuszczycy krostkowej $[10,11]$. Przypadek przedstawiamy, aby uwzględnić AGEP wśród zaburzeń wywołujących zjawisko koebneryzacji oraz zwrócić uwagę klinicystów na możliwość wystąpienia takiego obrazu schorzenia.

\section{KONFLIKT INTERESÓW}

Autorzy nie zgłaszają konfliktu interesów. 


\section{References}

\section{Piśmiennictwo}

1. De A., Das S., Sarda A., Pal D., Biswas P.: Acute generalised exanthematous pustulosis: an update. Indian J Dermatol 2018, 63, 22-29.

2. Roujeau J.C., Bioulac-Sage P., Bourseau C., Guillaume J.C., Bernard P., Lok C., et al.: Acute generalised exanthematous pustulosis. Analysis of 63 cases. Arch Dermatol 1991, 127, 1333-1338.

3. Burrows N.P., Russell Jones R.R.: Pustular drug eruptions: a histopathological spectrum. Histopathology 1993, 22, 569-573.

4. Duman H., Topal I.O., Kocaturk E., Cure K., Mansuroglu I.: Acute generalized exanthematous pustulosis induced by hydroxychloroquine: a case with atypical clinical presentation. An Bras Dermatol 2017, 92, 404-406.

5. Navarini A.A., Valeyrie-Allanore L., Setta-Kaffetzi N., Barker J.N., Capon F., Creamer D., et al.: Rare variations in IL36RN in severe adverse drug reactions manifesting as acute generalised exanthematous pustulosis. J Invest Dermatol 2013, 133, 1904-1907.

6. Gabay C., Towne J.E.: Regulation and function of interleukin-36 cytokines in homeostasis and pathological conditions. J Leukoc Biol 2015, 97, 645-652.

7. Szatkowski J., Schwartz R.A.: Acute generalised exanthematous pustulosis (AGEP): a review and update. J Am Acad Dermatol 2015, 73, 843-848

8. Britschgi M., Pichler W.J.: Acute generalised exanthematous pustulosis, a clue to neutrophil-mediated inflammatory processes orchestrated by T cells. Curr Opin Allergy Clin Immunol 2002, 2, 325-331.

9. Sagi L., Trau H.: The Koebner phenomenon. Clin Dermatol 2011, 29, 231-236.

10. Sidoroff A., Halevy S., Bavinck J.N., Vaillant L., Roujeau J.C.: Acute generalized exanthematous pustulosis (AGEP) - a clinical reaction pattern. J Cutan Pathol 2001, 28, 113-119.

11. Auer-Grumbach P., Pfaffenthaler E., Soyer H.P.: Pustulosis acuta generalisata is a post-streptococcal disease and is distinct from acute generalized exanthematous pustulosis. Br J Dermatol 1995, 133, 135-139.

Received: 21.02 .2020

Accepted: 14.08 .2020

Otrzymano: $21.02 .2020 \mathrm{r}$.

Zaakceptowano: $14.08 .2020 \mathrm{r}$.

How to cite this article

Dorjay K., Sachdeva S., Sinha S.: Isomorphic response in a case of quinolone-induced acute generalized exanthematous pustulosis. Dermatol Rev/Przegl Dermatol 2020, 107, 454-458. DOI: https://doi.org/10.5114/dr.2020.101673. 